\title{
April sea ice extent in the Barents Sea, 1850-2001
}

\author{
Inna Shapiro, Roger Colony \& Torgny Vinje
}

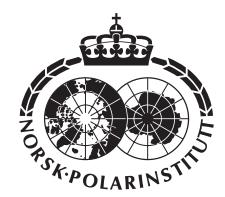

Three observational data sets are used to construct a continuous record (1850-2001) of April ice edge position in the Barents Sea: two sets of Norwegian ice charts (one from 1850 to 1949 and the other from 1966 to 2001) and Soviet aircraft reconnaissance ice extent charts from 1950 to 1966. The 152-year April ice extent series is subdivided into three sub-periods: 1850-1899, 1900-1949 and 1950-2001. For each of these study sub-periods, a mean April ice edge and a set of anomalies (differences in position between a given April and the mean April ice edge) are computed. The calculations show the mean ice edge position retreated north-eastward over the 152-year period, with the greater retreat seen in the changes from the 1850-1899 sub-period to the 1900-1949 sub-period. The distribution of the standard deviation of the ice edge anomaly over the linear distance along the mean ice edge shows no substantial difference between any of the three periods of the study. Within each study period, the maximum variation is observed in the sector bounded by the $25^{\circ} \mathrm{E}$ and $49^{\circ} \mathrm{E}$ meridians, which covers the main pathway of the warmer water flow from the Norwegian Sea.

I. Shapiro, R. Colony \& T. Vinje, International Arctic Research Center, University of Alaska Fairbanks, 930 Koyukuk Drive, Box 757335, Fairbanks, AK 99775, USA, inna@iarc.uaf.edu.

In nature, ice edge position is sometimes welldefined and sometimes ill-defined. After persistent on-ice wind, a few tens of metres can separate compact ice cover from the open sea. During ice melt and with off-ice wind, loose ice can be scattered over several hundred kilometres. The scientific literature often contributes to confusion regarding a defined ice edge, and for many problems we are better served by reference to a marginal ice zone. For climate research, there may be merit in regarding ice edge position as a primary variable and defining appropriate statistics.

In this study, we define ice edge as the isopleth of $30-40 \%$ ice concentration. On one side of the boundary less than $30-40 \%$ of the sea surface is covered by ice; on the other side more than $30-40 \%$ of the sea is covered. The $30 \%$ ice coverage has historical relevance: it is the maximum ice cover in which sailing vessels can easily manoeuvre.

Using a combination of ship, aircraft and satel- lite observations, we estimate the mid-April ice edge position for the period 1850-2001. The ice edge position is then regarded as a random variable, and we are provided with 152 realizations. Definitions of the mean and variance are developed and sample statistics are estimated.

\section{Data}

Our study uses three data sets to construct a continuous observational record of April ice edges in the Barents Sea from 1850 to the present. Norwegian ice charts comprise two of the data sets: the first from 1850 to 1949 , and the second from 1966 to 2001. Soviet reconnaissance aircraft collected Barents Sea ice edge data for the intervening years, 1950-1966.

The study's geographic domain is limited to the Barents Sea, a region of the Arctic Ocean extending from Svalbard to Novaya Zemlya and south- 


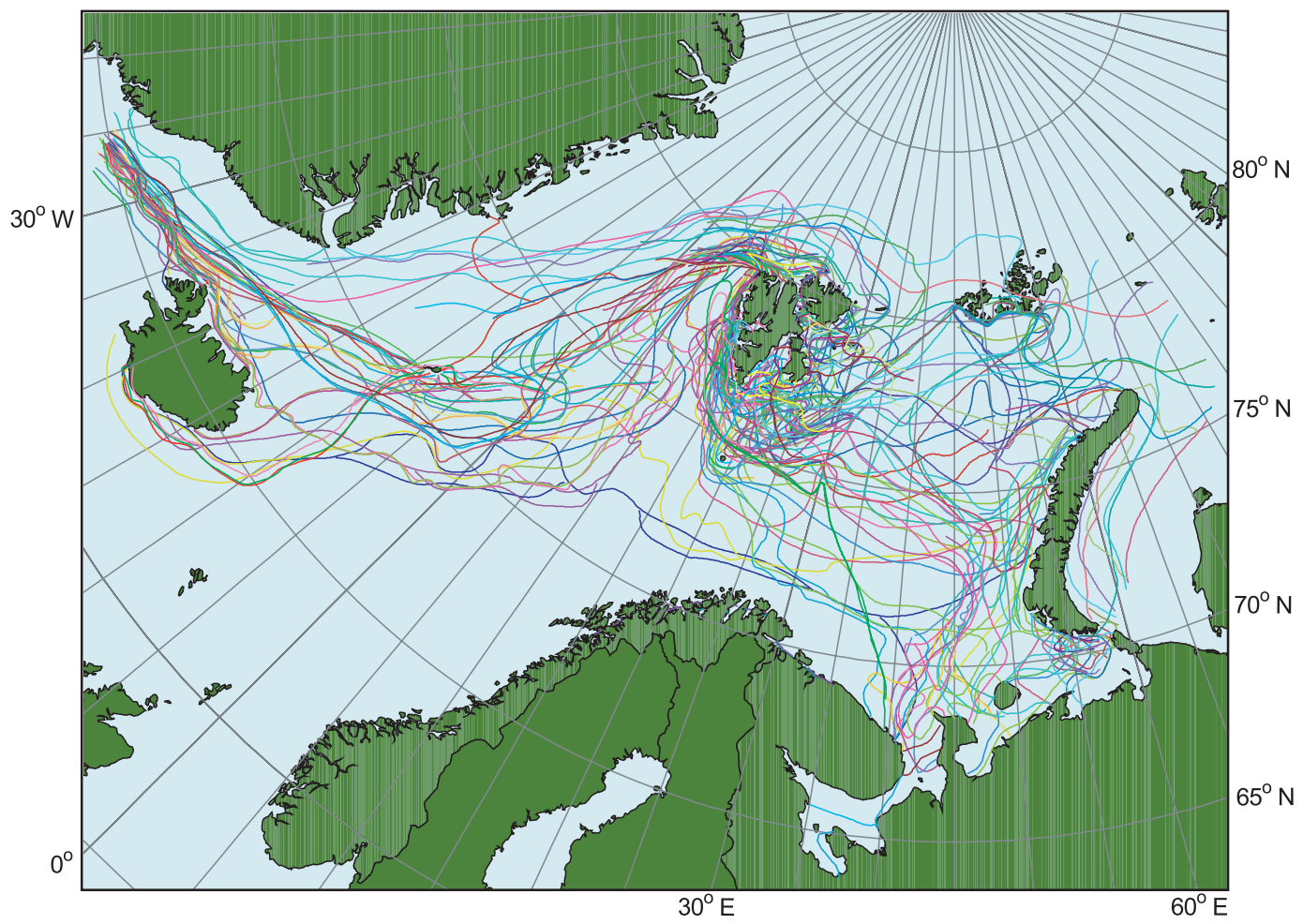

Fig. 1. Spring to autumn monthly ice extent for $1880-1889$, reconstructed from observations of ice edge position made by sealing and whale-hunting expeditions.

ward to the Kola Peninsula, roughly bounded by $5^{\circ}$ to $60^{\circ} \mathrm{E}$ in longitude and $67^{\circ}$ to $80^{\circ} \mathrm{N}$ in latitude. Ice edge positions are defined by a set of geographic coordinates, latitudes and longitudes, specifying the observed points along the ice edge. Data coverage, especially in the early part of the study period, is insufficient for daily or weekly analysis. The twice-monthly data are sufficient for analysis of the mid-month ice edge position. Furthermore, we select the April mean ice edge position for study of interannual ice edge variability, because the March/April ice edge extent has been viewed traditionally as the annual maximum ice edge extent (Vinje 1985).

\section{Norwegian charts, 1850-1949}

The Norwegian Polar Research Institute (NPI) organized and charted comprehensive observations of ice edge position gathered from annual March-to-September sealing and hunting expeditions in the Nordic seas. Starting in the early 1850 s, ships' logbooks formed the record of the ice edge positions, and made limited descriptions of sea ice type near the ice edge. The ice edge data and ice description were processed digitally at NPI. Figure 1 illustrates data from a typical 10year record from 1880 to 1889 .

For the 1850-1949 period, the ice extent observations for each year are combined into a biweekly ice map series, and each series is typically assigned the date of the last day within the corresponding fortnight. Figure 2 illustrates two such composite ice maps for 1912: one is dated 8 April and the other 22 April. In both cases the plot shows two ice extent lines, running relatively close to each other. The inner line bounds roughly the $7 / 10$ ice concentration, and the seaward boundary corresponds to an approximate $3 / 10$ ice concentration. The ice edge shown on this figure is a combination of several ice extent lines, each corresponding to a different ice extent observational record. These lines sometimes overlap, and sometimes have small gaps of several tens of kilometres between them. In our calculations, we use the seaward ice boundary as the April ice extent, combine the lines from different records into a single ice extent line and, for anomaly cal- 


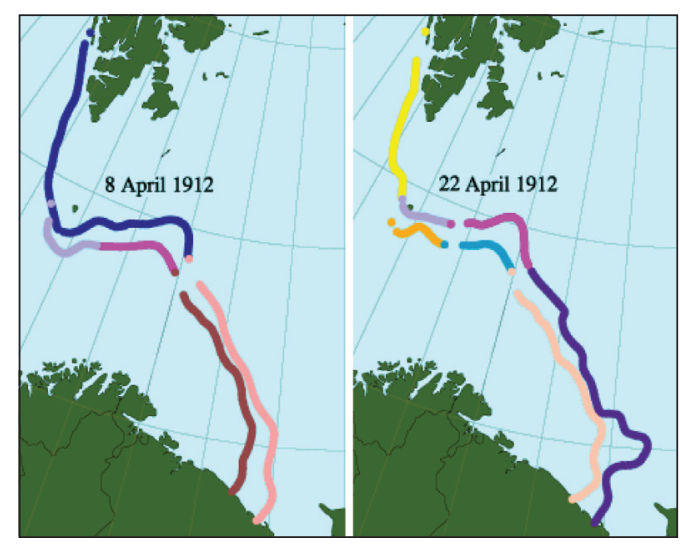

Fig. 2. April 1912 ice edge position-an example of the ice extent measurements based on ships' logbook records and reconstructed digitally at the Norwegian Polar Institute.

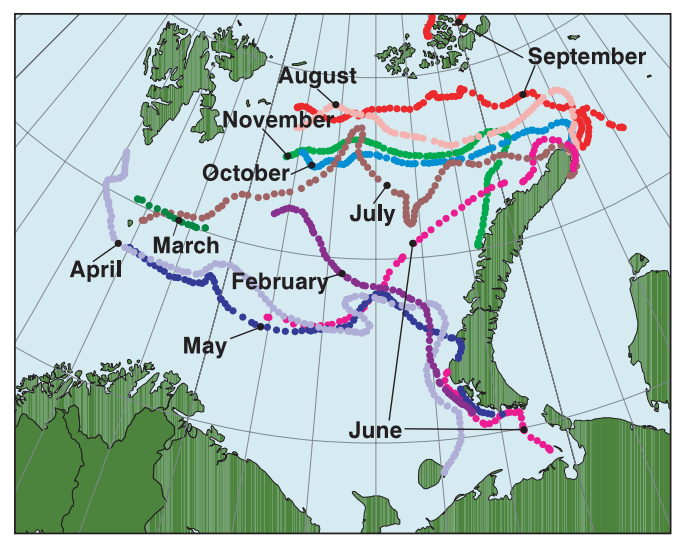

Fig. 3. 1962 monthly ice extent from Soviet aircraft observations.

Fig. 4. Ice chart for 18 April 1988 - an example of a modern Norwegian ice chart using high resolution satellite data as well as data from ships and aircraft. Ice concentrations are as follows: very close drift ice $(9 / 10-10 / 10)$; close drift ice $(7 / 10-9 / 10)$; open drift ice $(4 / 10-7 / 10)$; very open drift ice $(1 / 10-4 / 10)$; and open water $(0 / 10-1 / 10)$.
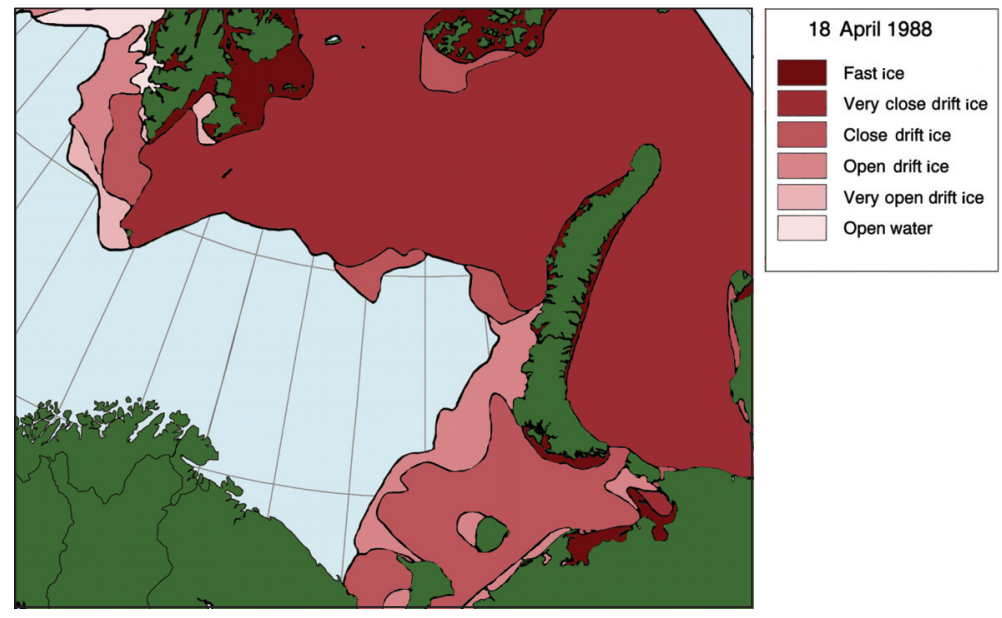

culations, we linearly interpolate the small gaps between lines from different records.

\section{Soviet aircraft reconnaissance, 1950-1966}

The ice-covered seas played a strategic role for Soviet national security during the Cold War, and Soviet Air Force aircraft charted the ice edge on a regular basis. The Soviet aircraft reconnaissance ice edge data typically consist of a single ice extent line. Figure 3 is an example of a composite ice chart for 1962 and is a typical record of Soviet Air Force ice edge observations contained in the Environmental Working Group joint U.S.Russian sea ice atlas (Arctic Climatology Project 2000).
Norwegian ice charts, 1966-2001

Modern ice charts provide high resolution data for ice edge position and sea ice type. Such charts have been compiled routinely by the Norwegian Meteorological Institute since 1966, the US Navy/NOAA Joint Ice Center (now the National Ice Center) since 1972, and the UK Meteorological Office. These three ice map series were intercompared for quality control and to obtain a consistent modified series for the NPI digitization work.

High quality, all-weather satellite data have been available since 1979. Today's ice charts are produced using data from ships and aircraft, as well as the $1.5 \mathrm{~km}$ and $25 \mathrm{~km}$ resolution satellite data. Figure 4, an ice map for 18 April 1988, is 
an example of a modern ice chart. Ice types are described as one of six categories in a continuum (ice concentration in parentheses): open water $(0 / 10$ - 1/10); very open drift ice $(1 / 10-4 / 10)$; open drift ice (4/10-7/10); close drift ice (7/10-9/10), very close drift ice $(9 / 10-10 / 10)$; and fast ice. A description of the NPI ice charts series is given in Vinje (2001).

Working with contemporary Norwegian ice charts for the 1966-2001 period, we used the boundary between open drift ice and very open drift ice-a 4/10 ice concentration line-as the April ice extent line.

\section{Statistical technique}

Our study's underlying premise is that direct observations of sea ice extent are suitable for quantitative study and standard statistical tools may be used to test plausible hypotheses. We treat each annual April ice edge position as an independent sample estimating the true mean ice edge for the month. The total 152-year observational record is subdivided into three sub-periods, each spanning approximately 50 years: 1850-1899, 1900-1949 and 1950-2001. We define anomalies as differences in position between a given April and the ensemble mean of all April ice edges over the corresponding study sub-period, and we compute first- and second-moment statistics for the set of observed April ice edges.

\section{Observed ice edge as a random line}

For each year of the 152-year observational record, the April ice edge is described by the available set of observed latitudes and longitudes. In some years, there is more than one set of April ice edge observations. In these cases, the mean April ice edge for the year is selected as the complete set of ice edge observations in April closest to 15 April. In cases where two sets of ice edge observations are equally close to 15 April, the later set is selected.

\section{Postulated mean, parametric representation, and definition of perpendiculars}

The mean ice edge position is a vector function in a rectangular coordinate system with the origin at the North Pole, $\mathrm{x}$ axis corresponding to the Greenwich meridian, and y axis corresponding

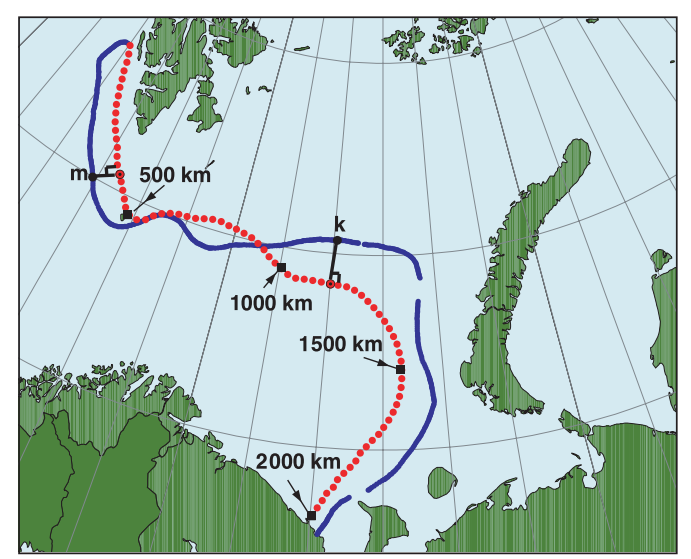

Fig. 5. Mean April ice edge, 1900-1949 (red dotted line) and observed ice edge, April 1924 (blue line).

to the $90^{\circ} \mathrm{E}$ meridian. It is parameterized by arc length distance, $s$ :

$$
\overline{\mathbf{x}}=\overline{\mathbf{x}}(s)=[x(s), y(s)]
$$

Here, $s$ is the distance $(\mathrm{km})$ measured along the ice edge from the west coast of Svalbard to the Kola Peninsula.

We define the annual anomaly of ice edge location, $\varphi(s)$, as the perpendicular distance from the observed ice edge to the mean at sample points along the mean ice edge on $25 \mathrm{~km}$ spacing. By convention, positive anomalies are associated with increases in ice extent, while negative anomalies are associated with decreases in ice extent. The scalar ice edge anomaly is easily recognized when the observed ice edge and the mean ice edge are roughly parallel. For cases where the perpendicular from the observed ice edge to the mean intersects the observed ice edge at more than one point (e.g. where the observed ice edge contains a peninsula or salient extending from the general trend of the ice edge), the anomaly is defined as the minimum value of this perpendicular distance. Figures 5 and 6 illustrate an example, the April anomaly for 1924. In this example, the distance $|\varphi(s)|$ is the shortest distance from the observation to the mean and defines the position along the mean. Two sample points have been selected to illustrate the anomaly distance, the first point, $m$, at $s=350 \mathrm{~km}$ and the second point, $k$, at $s=1150 \mathrm{~km}$. The graph of anomaly by distance for the April 1924 case is shown in Fig. 6, and the sample points of Fig. 5 are labelled together with their corresponding anomalies.

April sea ice extent in the Barents Sea 


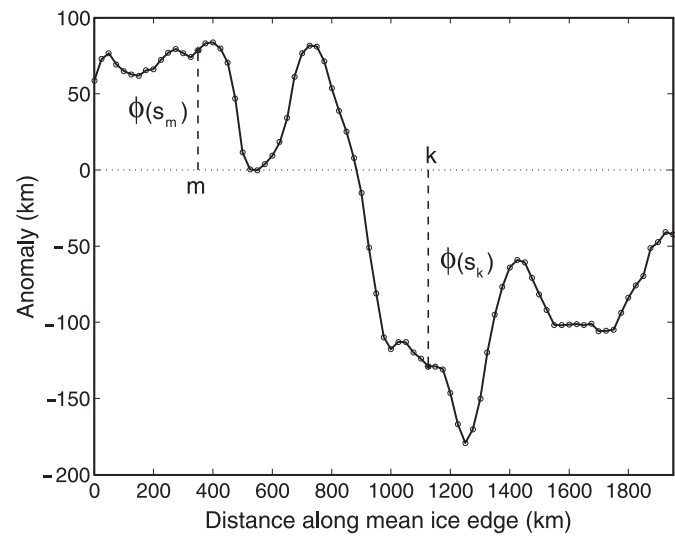

Fig. 6. Ice edge anomaly, April 1924.

The anomaly is regarded as a random variable. The anomaly, $\varphi(s)$, has the advantage of being a scalar function of the scalar distance. The mean monthly ice edge over the study period must therefore satisfy the condition:

$$
\mathbf{E}\{\varphi(s)\}=0
$$

\section{April mean ice edge}

\section{Iteration of mean and importance of the smooth mean}

April ice edges over the three study sub-periods (1850-1899, 1900-1949 and 1950-2001) are plotted for purposes of estimating a provisional mean. Based on the provisional mean, the set of anomalies for each study sub-period is estimated. Subject to the condition of Eq. (2), the mean is re-estimated and the new set of anomalies is recalculated. This approach combines the advantage of a reasonable representation of the mean ice position with preservation of the statistical integrity and robustness of the data.

The smoothing technique uses a first-guess April mean ice edge for each study sub-period. After anomalies are computed, the condition of Eq. (2) is imposed, and the mean ice edge is adjusted to satisfy the condition. Several iterations of this process are needed typically to arrive at an ice edge estimate that meets the zero-anomaly condition. A Savitzki-Golay smoothing filter (also called digital smoothing polynomial filter or least-squares smoothing filter) is used to make the

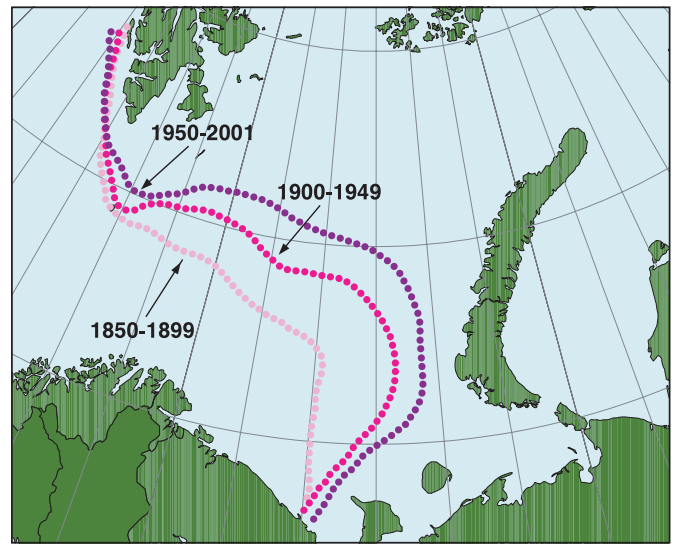

Fig. 7. Mean April ice extent: 1850-1899, 1900-1949 and 1950-2001.

ice edge relatively smooth (Orfanidis 1996).

Additionally, several trials are performed with different first-guess ice edges to test the robustness of the technique. It is found that the resulting mean ice edge solutions are nearly identical after the conditions of Eq. (2) are imposed, regardless of which ice edge position is used as a first guess. The mean ice edge positions for each study subperiod are shown in Fig. 7. We note here that the mean ice edge position appears to have retreated north-eastward over the 152-year overall period, and that the retreat is greater from the 1850 1899 sub-period compared to the 1900-1949 sub-period, then from the 1900-1949 sub-period compared to the 1950-2001 sub-period.

\section{Variance of the ice edge}

We define the variance of the ice edge position:

$$
\begin{gathered}
\sigma^{2}(s) \equiv \operatorname{var}\{\varphi(s)\}=\mathbf{E}\left\{\varphi^{2}(s)\right\}, \text { or } \\
\sigma^{2}=\frac{1}{L} \int \operatorname{var}\{\varphi(s)\} d s
\end{gathered}
$$

where $L$ is the path length along the ice edge (in $\mathrm{km})$. The spatially homogeneous variances are $\sigma^{2}=2.48 \times 10^{4} \mathrm{~km}^{2}(1850-1899), \sigma^{2}=1.43 \times 10^{4}$ $\mathrm{km}^{2}(1900-1949)$ and $\sigma^{2}=1.3 \times 10^{4} \mathrm{~km}^{2}(1950$ 2001).

Figure 8 shows the standard deviation (the square root of the variance, computed in Eq. [3]) of the ice edge anomaly from the mean ice edge for each of the three sub-periods of the study. Figure 8 suggests little variation in the standard deviation of the anomaly between different study 

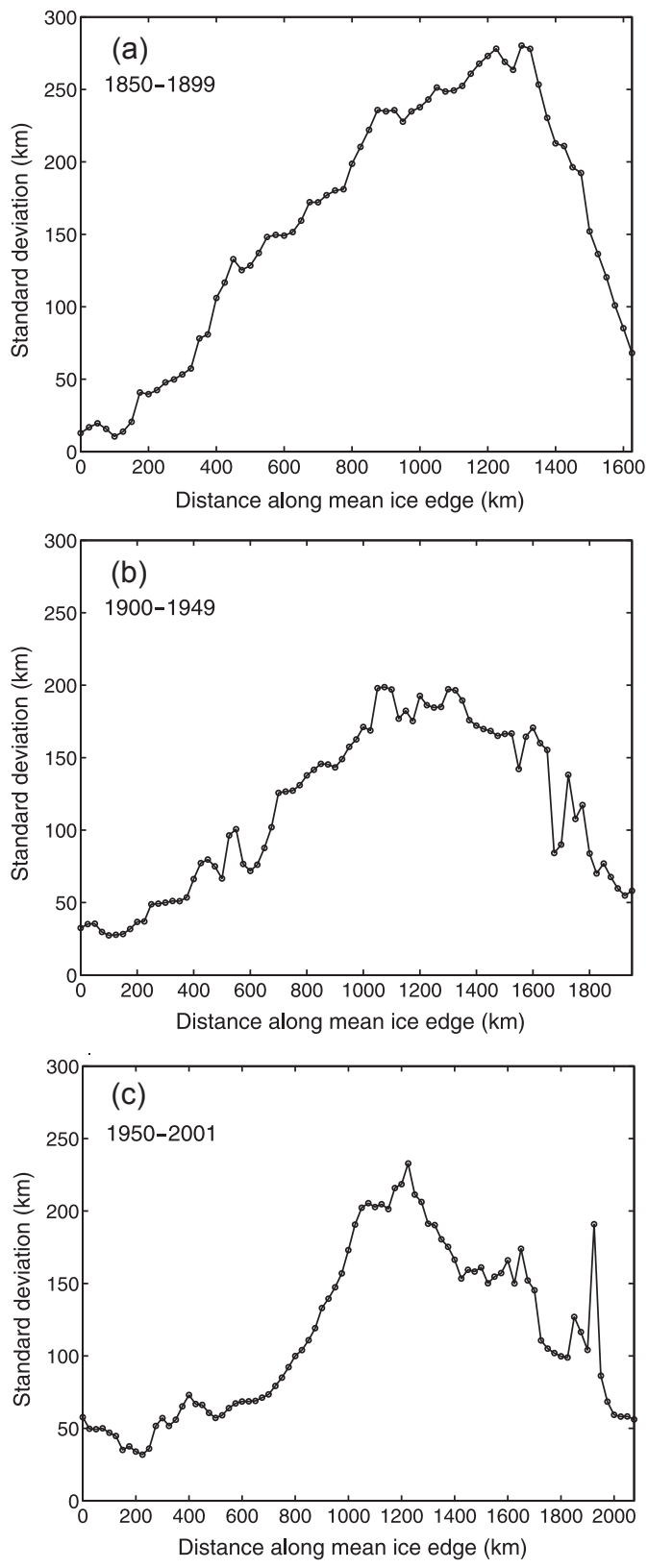

Fig. 8. Standard deviation of the ice edge anomaly: (a) April 1850-1899; (b) April 1900-1949; and (c) April 1950-2001.

sub-periods, indicating that although the mean ice edge changes location from one study period to another, the variance of the ice edge within each study sub-period is essentially unchanged. Within each study sub-period, the least variation is in the beginning segments (near Svalbard) and the ending segments (near the Kola Peninsula), with maximum variation between 800 and $1600 \mathrm{~km}$ along the ice edge. This zone of maximum variance corresponds to the sector bounded by the $25^{\circ}$ and the $49^{\circ} \mathrm{E}$ meridians, and covers the main pathway of the throughflow of the warmer Atlantic water from the Norwegian Sea (Loeng et al. 1997).

\section{Conclusions}

The analysis of the continuous observational record of April ice edge in the Barents Sea shows the retreat in the mean ice edge position from 1850 to present. The 152 -year record is comprised of three study periods, each approximately 50 years long, and comparison between these periods indicate largest retreat in ice edge from the pre-industrial (1850-1899) era to the first half of the 20th century. Ice in the Barents Sea continues to retreat during the last half of the 20th century.

We conclude that the distribution of the standard deviation of the ice edge anomaly from the mean ice edge over the linear distance along the mean ice edge shows no substantial difference between any of the three periods of the study, while the largest variability of standard deviation within each study period corresponds to the area of warm Atlantic water inflow to the Barents Sea from the Norwegian Sea.

Acknowledgments.-This work was supported by the Frontier Research System for Global Change. The authors thank H. Goodwin for help with the data set, T. Shy for helpful suggestions and two reviewers for their constructive comments.

\section{References}

Arctic Climatology Project 2000: Environmental Working Group joint U.S.-Russian sea ice atlas. F. Tanis \& V. Smolyanitsky (eds.). CD-ROM. Ann Arbor, MI: Environmental Research Institute of Michigan in association with the National Snow and Ice Data Center.

Loeng, H., Ozhigin, V. \& Adlandsvik, B. 1997: Water fluxes through the Barents Sea. ICES J. Mar. Sci. 54, 310-317.

Orfanidis, S. J. 1996: Introduction to signal processing. Englewood Cliffs, NJ: Prentice-Hall.

Vinje, T. 1985: Drift, composition, morphology and distribution of the sea ice fields in the Barents Sea. The physical environment, western Barents Sea. Nor. Polarinst. Skr. 179 C. Oslo: Norwegian Polar Institute.

Vinje, T. 2001: Anomalies and trends of sea-ice extent and atmospheric circulation in the Nordic seas during the period 1864-1998. J. Clim. 14, 255-267.
April sea ice extent in the Barents Sea 